\title{
Youth Friendly Reproductive Health Service Utilization and Associated Factors Among School Youths in Ambo Town, Oromia Regional State, Ethiopia, 2018
}

\author{
Amerti Fikadu ${ }^{1}$, Elias Teferi², Mulugeta Mekuria ${ }^{2,}$, , Adamu Birhanu ${ }^{3}$, Tsegaye Benti \\ ${ }^{1}$ West Shoa Zone Health Office, Ambo, Ethiopia \\ ${ }^{2}$ Department of Public Health, College of Medicine and Health Science, Ambo University, Ambo, Ethiopia \\ ${ }^{3}$ Department of Psychiatry, College of Medicine and Health Science, Ambo University, Ambo, Ethiopia \\ Email address: \\ mule201160@yahoo.com (M. Mekuria) \\ ${ }^{*}$ Corresponding author
}

\section{To cite this article:}

Amerti Fikadu, Elias Teferi, Mulugeta Mekuria, Adamu Birhanu, Tsegaye Benti. Youth Friendly Reproductive Health Service Utilization and Associated Factors Among School Youths in Ambo Town, Oromia Regional State, Ethiopia, 2018. American Journal of Health Research. Vol. 8, No. 4, 2020, pp. 60-68. doi: 10.11648/j.ajhr.20200804.12

Received: July 17, 2019; Accepted: August 29, 2019; Published: July 4, 2020

\begin{abstract}
Background: Youth is a period of life in which an individual passes from significant physiological, psychological and social changes that expose them at high risk of reproductive health problems. The reproductive health problems in this period are preventable provided that youth utilize quality reproductive health services. The aim of the study was to assess the extent of youth friendly reproductive health services utilization and the associated factors among secondary and preparatory school youths in Ambo Town. Methods: Institutional based cross-sectional study was conducted among 376 youths who were attending the secondary and preparatory school in Ambo town from March, 1-30/2018. Simple random sampling method was used to select the study participants from each grade. Data were collected by trained data collectors using a pre-tested structured questionnaire. The collected data were entered into SPSS version 20 for analysis. Multiple logistic regression analyses were performed to identify the strength of association between dependent and independent variables at $95 \%$ confident interval and $\mathrm{P}$ value $<0.05$. Results were presented using tables and figures based on the nature of the variables. Result: About $20.7 \%$ of the youths had utilized youth friendly reproductive health services at least once in the last twelve months prior to the study. On a multivariable logistic regression analysis variable such as age $[\mathrm{AOR}=0.38,95 \% \mathrm{CI}=0.176-0.819]$, student grade $[\mathrm{AOR}=3.0,95 \% \mathrm{CI}=1.499-6.230]$, previous residence status $[\mathrm{AOR}=0.53,95 \% \mathrm{CI}=0.300-0.926]$ and the existence of youth friendly reproductive health service facility around living area $[\mathrm{AOR}=7.700,95 \% \mathrm{CI}=2.931-20.423]$ were significantly associated with youth friendly reproductive health service utilization. Conclusion: Youth friendly reproductive health services utilization among secondary and preparatory school youths in Ambo town was low. Age of the respondents, student grade, and previous residence status of the respondents \& existence of youth friendly reproductive health service health facilities were among predictors of youth friendly reproductive health services utilization. Therefore the Ambo town and, Ambo district health offices, Ambo town education offices and other organizations working in area of youths reproductive health services are recommended to give awareness on youth friendly service utilization through provision of training for youths.
\end{abstract}

Keywords: Youths, Reproductive Health, Utilization, Ambo Town

\section{Introduction}

Youths are persons between 15 to 24 years of age and accounts about $20 \%$ of the world's population, of whom $85 \%$ live in developing countries [1]. In Ethiopia there are about 21 million, youths and adolescents ages 10 to 24 years which accounts approximately $20 \%$ of the total population in the country $[2,3]$.

Youth friendly reproductive health services are services that are: accessible, acceptable, and appropriate for adolescents and youths. It is comprehensive essential services packages which includes provision of family planning and 
relevant SRH information, STI syndrome management, pregnancy test, provision of medical care service, provision of VCT/PITC, psychological support and counseling of GBV and sexual abuse, and referral linkage for services like ART, HIV/AIDS care and support of services to the whole target group $[4,5]$.

The onset of adolescence brings not only changes to their bodies but also new vulnerabilities to human rights abuses, particularly in the area of sexuality, marriage and child bearing. Millions of girls are coerced into unwanted sex or marriage, putting them at risk of unwanted pregnancies, unsafe abortions, sexually transmitted infections (STIs) including HIV, and complication of child birth. Young people both boys and girls are disproportionately affected by HIV [6]. An estimated 1.3 million adolescent girls and 780,000 adolescent boys are living with HIV worldwide [7]. In SubSaharan Africa, slightly more than half of all people living with HIV are women and girls and young women aged 15-24 years are as much as eight times more likely than men to be HIV positive [8].

Among the many sexual and reproductive health problems faced by youth in Ethiopia are gender inequality, sexual coercion, early marriage, polygamy, female genital cutting, unplanned pregnancies, closely spaced pregnancies, abortion, sexually transmitted infections (STIs), and AIDS. Lack of education, unemployment and extreme poverty exacerbate and perpetuate the reproductive health problems of Ethiopian youth [9].

Throughout the world youths are exposed to health risks because they often do not have adequate knowledge and guidance about sexual and reproductive health (SRH) [10]. They tend to be less informed, less experienced, and less comfortable in accessing reproductive health services than adults. In addition most of them do not feel comfortable in discussing reproductive health issues with their parents [11, 12] and access and utilization of youth friendly reproductive health services is limited due to socio-demographic, judgmental attitude of service providers, lack of confidentiality and privacy, costs and an unfavorable attitude of parents and negative community perceptions towards health seeking behaviors of adolescents and youths [13].

Globally many reproductive health services challenges confront young people and more pervasive in developing countries where the services and facilities are absent [14]. Youths in Ethiopia face many Reproductive health problems including gender inequality, sexual coercion, early marriage, unplanned pregnancies, abortion and sexually transmitted infections, including AIDS. Lack of education, unemployment, and extreme poverty exacerbates the reproductive health problems faced by Ethiopian youth [15].

According to demographic health survey $13 \%$ of girls aged 15-19 in Ethiopia have begun child bearing. This is associated with low use of modern contraceptives and limited access to youth friendly services [16] which in turn contributes to high rates of maternal mortality and morbidity [17]. Unmet need for contraceptives among sexually active unmarried young women is still as high as $26 \%$. On top of this only a quarter of young women and 39\% percent of young men aged 15-24 had comprehensive knowledge of HIV and its transmission [16]. Therefore, the purpose of this study is to assess utilization of youth friendly reproductive health services and identify the gap in provision of the services in the study area.

\section{Methods and Materials}

\subsection{Study Design and Setting}

Institution based cross sectional study was conducted among secondary and preparatory school youths, in Ambo town from March, 1- 30/2018. Ambo town is located in West Shewa zone, Oromia regional state at a distance of $114 \mathrm{~km}$ to the west of Addis Ababa, the capital city of Ethiopia. According to the report obtained from Ambo town office, the total population of the town is estimated to be more than 83,053 of which around 16,611 are between the ages of $15-$ 24 years. The town has four government schools of which three of them are secondary schools and one is preparatory school. In these schools there were 7,041 students whose ages were between 15-24 during the study period. In the town there are two hospital, (one referral and one general hospitals), 2 public health centers, 27 clinics and three health posts rendering heath services for the community [18]. According to Ambo town Health office report, only one public health center was providing youth friendly reproductive health services in the town and about 3,349 of youths utilized YFRHS in 2017 [19].

\subsection{Study Participants}

Youths attending regular program in Ambo secondary and preparatory schools were included in the study while students who were unable to see or hear and critically ill were excluded from the study.

\subsection{Sample Size and Sampling Techniques}

In calculating the sample size, single proportion formula was utilized by taking $\mathrm{P}=37.2 \%$ from study conducted in Bale zone, Goba town [20], 95\% confidence interval, $\alpha=0.05$ margin of error and $d=5 \%$ degree of precision. Since the source population is less than 10,000 the population correction formula was utilized. Finally, adding $10 \%$ of nonresponse rate 376 was sample size calculated.

All of the government schools in the town were included in the study. Proportional sample size allocation was used in selecting and including respondents, both male and female from each grade. Then simple random sampling was used to select study participants using their ID numbers as a sampling frame.

\subsection{Data Collection}

Four diploma nurses and two BSc were recruited as data collector and supervisors respectively. Prior to data collection, one day training was given for both data collectors 
and supervisors.

\subsection{Measurements}

The mean for knowledge about YFRHS was calculated based the knowledge questions and the calculated mean was considered as the cut-off point. Values below the mean were considered as poor knowledge while values above the mean were considered as good knowledge.

\subsection{Data Analysis}

The collected data were coded, cleaned and entered into Epi Data 3.1 software and exported to SPSS computer software version 21 for analysis. A binary logistic regression was done to identify associations between the dependent and independent variables and P-value of $<0.25$ was taken to include the variable as candidate for multivariable logistic regression model. Multivariable logistic regression analysis was done to determine the association between dependent and independent variables using adjusted odds ratio with $95 \%$ confidence interval at significance level of $\leq 0.05$.

\subsection{Ethical Consideration}

Ethical clearance was obtained from Ambo University College of medicine and health sciences Ethical Review
Committee. Supportive letters were obtained from the town education office and school administrations. Permission was also obtained from individual respondent for age greater than 18 and from their parents for these respondents whose age was less than 18 years of age.

\section{Results}

\subsection{Socio-demographic and Economic Characteristics of Respondents}

A total of 376 students' age between 15-24 years participated in the study with $100 \%$ response rate. More than three-quarter $(83.8 \%)$ of the respondents belong to age group between 14-19 years with mean age of 17.39 and SD of \pm 4.17 of years. About $97.1 \%$ of the respondents are Oromo by Ethnicity and $50.3 \%$ were protestant followers by religion. The large proportion (95.7\%) of the respondents were single by marital status and $34.3 \%$ of them were grade nine by education level.

Regarding youth's parent occupation, $56.9 \%$ of youth's mothers were housewives and $47.3 \%$ of their fathers were farmers. About $34.6 \%$ of the respondent's father and $39.6 \%$ of the mothers attended primary education. From the total study participants, $1.9 \%$ of the respondents had pocket money of less than 50 ETB per month, (Table 1).

Table 1. Socio-demographic and economic characteristics of respondents in secondary and preparatory school of Ambo town, West Shoa Zone, Ethiopia, 2018 .

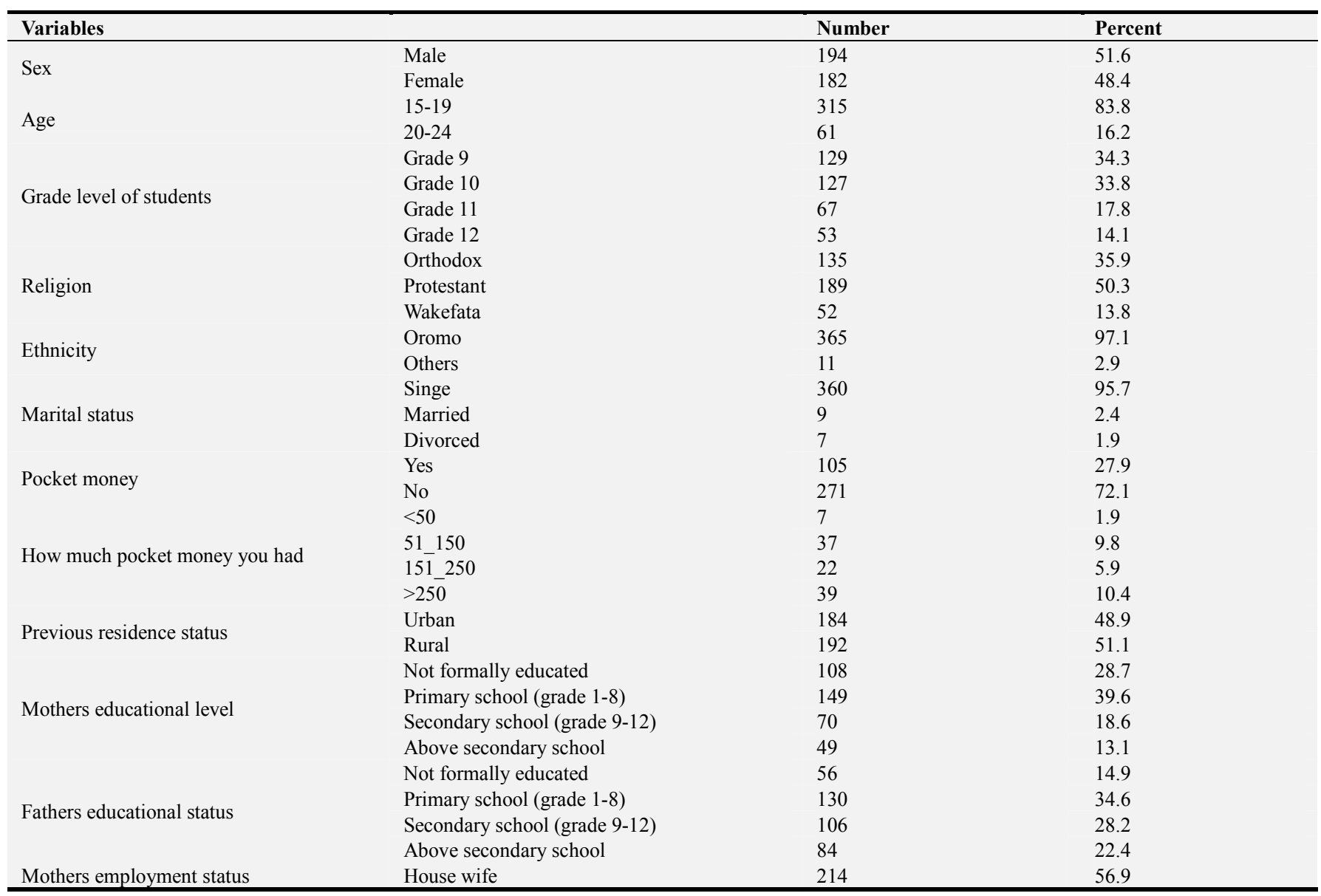




\begin{tabular}{llll}
\hline Variables & & Number & Percent \\
\hline & Employer & 46 & 12.2 \\
& Daily laborer & 24 & 6.4 \\
& Self-employment/Merchant & 84 & 22.3 \\
& Farmer & 8 & 2.2 \\
& Employer & 101 & 26.9 \\
Fathers employment status & Daily laborer & 21 & 5.6 \\
& Self employment/merchant & 76 & 20.2 \\
& Farmer & 178 & 47.3 \\
With whom Currently live with? & with both father and mother & 266 & 70.7 \\
& with father only & 6 & 1.6 \\
& with mother only & 28 & 7.4 \\
& with friends & 48 & 12.8 \\
\hline
\end{tabular}

\subsection{Reproductive Health Information and Youth Friendly Reproductive Health Service Utilization}

About $82 \%$ of the respondents reported that they knew about youth friendly reproductive health services. More than half $(56.6 \%)$ of the respondents knew about VCT followed by $51.1 \%$ family planning. About $62.8 \%$ of the study participants knew the place where youth friendly reproductive services are available and $74.2 \%$ of them responded that they had the right to use the youth friendly reproductive health services. Only $26.1 \%$ of the study participants reported that they had a parental discussion about the issue of reproductive health service. Out of the total respondents $88 \%$ reported that they knew methods of preventing pregnancy. Among these $37.9 \%$ knew one type pregnancy prevention methods while the remaining $47.5 \%$ knew more than one type of pregnancy prevention methods. The most known pregnancy preventing methods by the respondents was pills $60.4 \%$ followed by $51.9 \%$ injectables.

Regarding the sources of information $54.5 \%$ heard from school, $48.9 \%$ from health care providers, $27.9 \%$ from peers, $23.1 \%$ from Radio, $18.6 \%$ from parents, $4.8 \%$ from posters and $2.4 \%$ get information from internet about youth friendly reproductive health services. Among the total respondents $59.4 \%$ had only one source of information and $40.6 \%$ had 2 and above source of information about youth friendly services. From the total respondents $64.6 \%$ of them had knowledge on youth friendly reproductive health services (table 2).

Table 2. Information and knowledge of reproductive and youth friendly services among respondents of secondary and preparatory schools in Ambo town, West Shoa zone, Ethiopian 2018.

\begin{tabular}{|c|c|c|c|}
\hline Variables & YFRHS Utilization & Frequency & Percentage \\
\hline \multirow{2}{*}{ Access to media } & Yes & 251 & 66.8 \\
\hline & No & 125 & 33.2 \\
\hline \multirow{2}{*}{ Know about YFRHS $(n=376)$} & Yes & 308 & 81.9 \\
\hline & No & 68 & 18.1 \\
\hline \multirow{2}{*}{ Know right to use YFRHS } & Yes & 279 & 74.2 \\
\hline & No & 97 & 25.8 \\
\hline Discuss about reproductive health issue with parents & Yes & 98 & 26.2 \\
\hline \multirow{2}{*}{ Know where to get YFRHS } & Yes & 236 & 62.8 \\
\hline & No & 140 & 37.2 \\
\hline \multirow{2}{*}{ Know about pregnancy preventive methods. } & Yes & 331 & 88 \\
\hline & No & 45 & 12 \\
\hline \multirow{2}{*}{ Know about STI } & Yes & 367 & 97.6 \\
\hline & No & 9 & 2.4 \\
\hline \multirow{6}{*}{ Sources of information (more than one answer is possible) } & School & 205 & $54.5 \%$ \\
\hline & Peer & 105 & $27.9 \%$ \\
\hline & Radio & 87 & $23.1 \%$ \\
\hline & Parents & 70 & $18.6 \%$ \\
\hline & Posters & 18 & $4.8 \%$ \\
\hline & Internet & 9 & $2.4 \%$ \\
\hline \multirow{2}{*}{ Level of knowledge about YFRHS } & Good Knowledge & 243 & 64.6 \\
\hline & Poor knowledge & 133 & 35.4 \\
\hline
\end{tabular}

\subsection{Availability and Utilization of Youth Friendly Reproductive Health Service}

About $71.5 \%$ of the respondents had awareness about the presence of the Youth friendly reproductive health services in their surroundings. Regarding the distance to health facility majority of respondents $(54.2 \%)$ responded it is preferable if it is available within the distance of less than 30 minutes for a single journey to reach the health centers to utilize Youth friendly reproductive health services by walk from residence.

Out of the total respondents only $20.7 \%$ the study participants reported that they ever used at least one youth 
friendly reproductive health service in the past twelve months. Out of $20.7 \%$, respondent who utilized the services in the last 12 months prior to the study, $82.1 \%$ of them received the services from government health centers, $12.8 \%$ of received the services from hospital and $5.1 \%$ of them received the services from private clinics.

Among the respondents who utilized the services, 65.5\% of the study participants said that they were requested to pay for the service and $38.5 \%$ were not requested. About $25.6 \%$ of the respondents said that the health facility working time was convenient and for $74.4 \%$ the time was was not convenient to use youth friendly reproductive health services. Among those who were asked the option of their convenient time to use the service, $24.1 \%$ mentioned that weekend as a convenient time followed by $17.3 \%$ early in the morning, $51.7 \%$ after noon and $6.9 \%$ public holly day.

Regarding health providers approach in providing the services $(44.9 \%)$ of them reported that they were handled in good friendly way and about $42.3 \%$ rated they are very with services given to them (Table 3 ).

Table 3. Health system factors of youth friendly reproductive health service utilization in secondary and preparatory schools of Ambo town.

\begin{tabular}{|c|c|c|c|}
\hline Variables & & Frequency & Percentage \\
\hline \multirow{2}{*}{ Awareness of existence of YFRHS in surrounding } & Yes & 269 & 71.5 \\
\hline & No & 107 & 28.5 \\
\hline \multirow{2}{*}{ Distance of the health facility from living area } & Less than 30 minutes & 146 & 54.2 \\
\hline & greater than 1 hour & 65 & 24.2 \\
\hline \multirow{2}{*}{ Ever used YFRH in the last 12 months } & Yes & 78 & 20.7 \\
\hline & No & 298 & 79.3 \\
\hline \multirow[t]{2}{*}{ Health facility utilized } & Hospitals & 10 & 12.8 \\
\hline & Private clinic & 4 & 5.1 \\
\hline \multirow{2}{*}{ Requested to pay for the service $(\mathrm{N}=78)$} & Yes & 48 & 65.5 \\
\hline & No & 30 & 38.5 \\
\hline \multirow{2}{*}{ Convenience of Health facility working time $(\mathrm{N}=78)$} & Yes & 20 & 25.6 \\
\hline & No & 58 & 74.4 \\
\hline \multirow[b]{2}{*}{ Health care providers approach $(\mathrm{N}=78)$} & Good friendly & 28 & 35.9 \\
\hline & Moderately welcomed & 35 & 44.9 \\
\hline \multirow{3}{*}{ How do you rate the service given $(\mathrm{N}=78)$} & Very satisfied & 30 & 38.5 \\
\hline & Satisfied & 33 & 42.3 \\
\hline & Not satisfied & 15 & 19.2 \\
\hline
\end{tabular}

\subsection{Types of Youth Friendly Reproductive Health Services Utilized by Respondents}

Regarding the utilization of youth friendly reproductive health services, $13.8 \%$ utilized VCT followed by $10.9 \%$ IEC. All of the study participants who have utilized the youth friendly services had used more than one type of service (Figure 1).

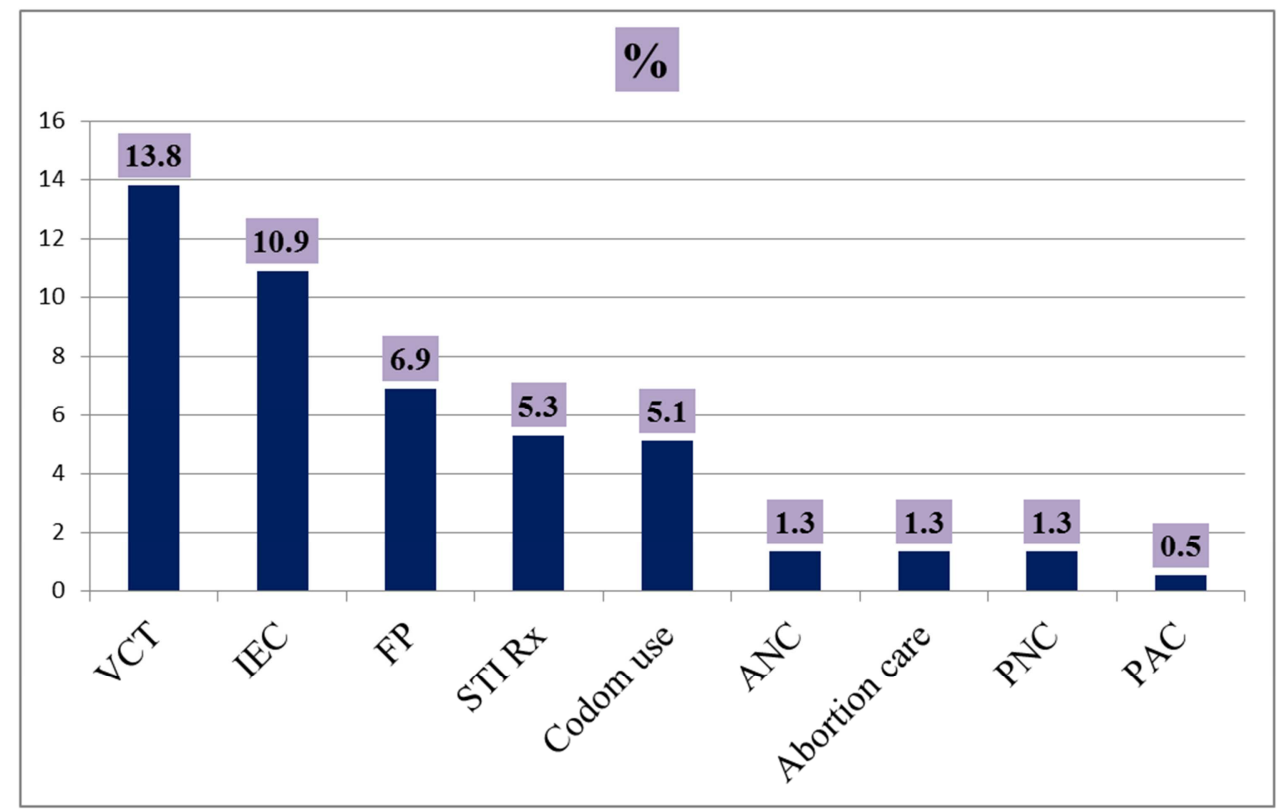

AOR-Adjusted OR: odds ratio by multiple logistic regression. 95\% CI: confidential interval. **: p-value $<0.05$.

Figure 1. YFRHS utilized among secondary and preparatory school youths in Ambo town 2018. 


\subsection{Reasons for Not Utilizing Youth Friendly Reproductive Health Services}

The result of this study revealed that three-fourth (79.3\%) of the study participants did not use YFRHS. The reason mentioned for not utilizing YFS was in about 35.9\% they did not want the services or they were not ill followed by $25.8 \%$ do not know where to go to get the services, $11.8 \%$ because of distance of the health services and had no money for the services, $8 \%$ inconvenient working hours and $6.7 \%$ fear of being seen by families or peoples whom they know (figure 2).

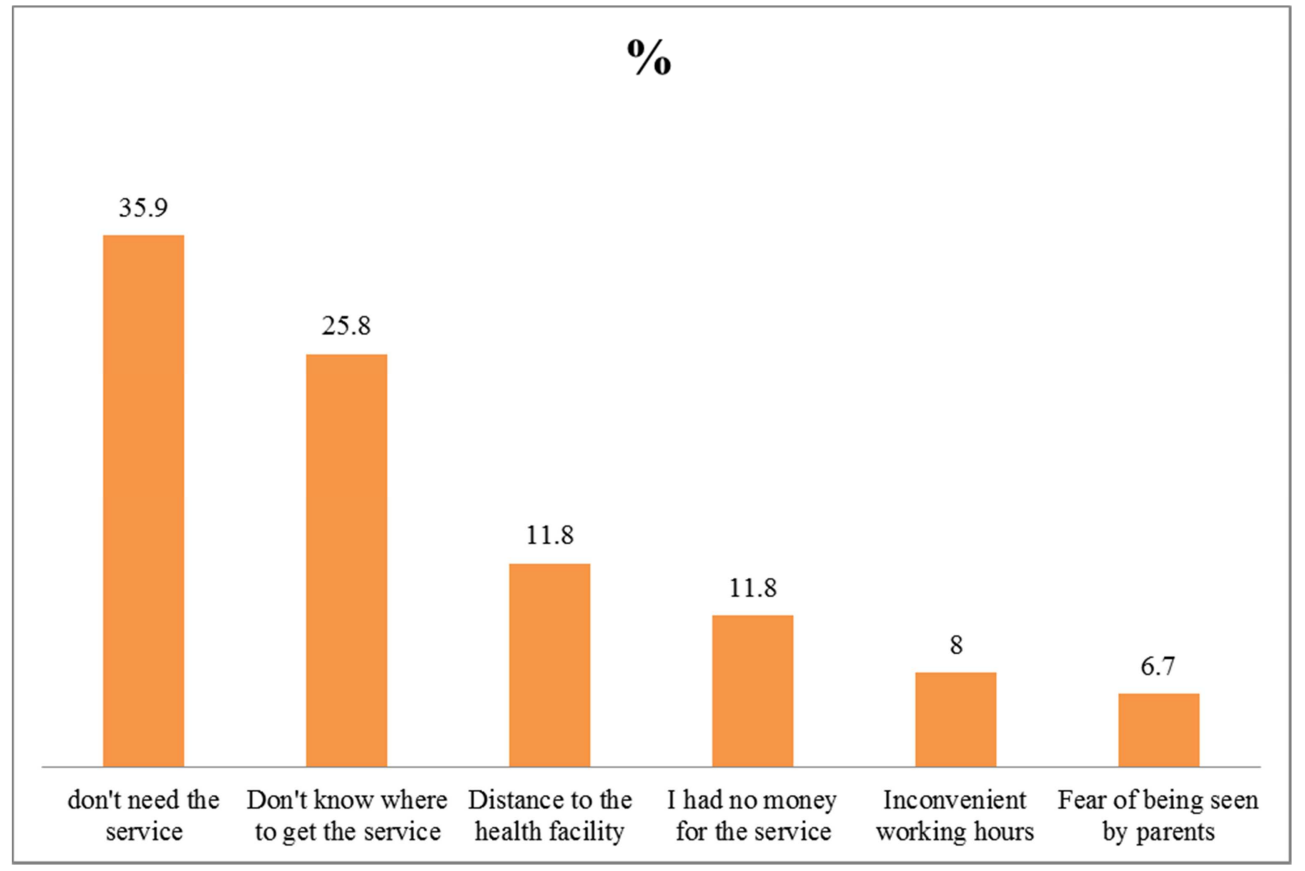

Figure 2. Reasons for not utilized youth friendly RH service by Secondary and preparatory school students of Ambo town, Oromia, Ethiopia, 2018.

\subsection{Factors Associated with Youth Friendly RH Service Utilization}

From nine variables which entered into multivariate logistic regression model only variables: age of the respondents, grade of the students, previous residence status and existence of youth friendly service facilities were found as predictors of outcome variable.

Table 4. Multivariate analysis of factors affecting youth friendly service utilization among secondary and preparatory school students in Ambo town, oromia, Ethiopia 2018.

\begin{tabular}{|c|c|c|c|c|c|}
\hline \multirow{2}{*}{ Variables } & \multirow{2}{*}{ Category } & \multicolumn{2}{|c|}{ Used YFRHS } & \multirow{2}{*}{$\operatorname{COR}(95 \%, \mathrm{CI})$} & \multirow{2}{*}{$\operatorname{AOR}(95 \%, C I)$} \\
\hline & & Yes & No & & \\
\hline \multirow{2}{*}{ Age } & $15-19$ & $59(18.7 \%)$ & $257(81.3 \%)$ & $.495(.268-.915)^{*}$ & $.380(.176-.819)^{* *}$ \\
\hline & $20-24$ & $19(31.1 \%)$ & $41(68.9 \%)$ & 1 & 1 \\
\hline \multirow{4}{*}{ Grade of the students } & Grade 9 & $35(27.1 \%)$ & $94(72.9 \%)$ & $2.583(1.346-4.959)^{*}$ & $3.0(1.499-6.23)^{* *}$ \\
\hline & Grade 10 & $16(12.6 \%)$ & $111(87.4 \%)$ & $1.014(.521-1.971)$ & $1.4(.674-2.977)$ \\
\hline & Grade 11 & $18(26.9 \%)$ & $49(73.1 \%)$ & $1.820(.805-4.114)$ & $2.6(.956-7.062)$ \\
\hline & Grade 12 & $9(17 \%)$ & $44(83 \%)$ & 1 & 1 \\
\hline \multirow{2}{*}{ Previous residence status } & Urban & $29(15.8 \%)$ & $155(84.2 \%)$ & $.546(.327-.911)^{*}$ & $.527(.3-.926)^{* *}$ \\
\hline & Rural & $49(25.5 \%)$ & $143(74.5 \%)$ & 1 & 1 \\
\hline \multirow{2}{*}{ Heard about YFRHS } & Yes & $74(24 \%)$ & $234(76 \%)$ & $.198(.07-.561)^{*}$ & $0.4(0.116-1.378)$ \\
\hline & No & $4(5.9 \%)$ & $64(94.1 \%)$ & 1 & 1 \\
\hline \multirow{2}{*}{ know where to get YFRHS } & Yes & $61(25.5 \%)$ & $175(74.2 \%)$ & $.397(.221-.712)^{*}$ & $0.8(.374-1.717)$ \\
\hline & No & $17(12.1 \%)$ & $123(87.9 \%)$ & 1 & 1 \\
\hline \multirow{2}{*}{ Know right to get YFRHS } & Yes & $69(24.7 \%)$ & $210(75.3 \%)$ & $.311(.149-.651)^{*}$ & $.7(.254-1.798)$ \\
\hline & No & $9(9.3 \%)$ & $88(90.7 \%)$ & 1 & 1 \\
\hline \multirow{2}{*}{ Know YFRHS is for proper care } & Yes & $71(22.7 \%)$ & $242(77.3 \%)$ & $.426(.186-.976)^{*}$ & $1.1(0.37-3.199)$ \\
\hline & No & $7(11.1 \%)$ & $56(88.9 \%)$ & 1 & \\
\hline \multirow{2}{*}{ Existence YFRHS facility } & Yes & $73(27.1 \%)$ & $196(72.9 \%)$ & $7.598(2.977-19.395)^{*}$ & $7.7(2.931-20.423)^{* *}$ \\
\hline & No & $5(4.7 \%)$ & $102(95.3 \%)$ & 1 & 1 \\
\hline
\end{tabular}


Age of the respondents, within range 15-19 years $[\mathrm{AOR}=0.38,95 \% \mathrm{CI}=(0.176-0.819)]$, being in grade nine $[\mathrm{AOR}=3.0,95 \% \quad \mathrm{CI}=(1.499-6.23)]$, students residence $[\mathrm{AOR}=0.527,95 \% \mathrm{CI}=(0.300-0.926)]$ and existence of YFRHS facilities around the surrounding of the respondents $[\mathrm{AOR}=7.7(2.931-20.423)]$ were the variables that showed the significant association with youth friendly $\mathrm{RH}$ service in this study (Table 4).

\section{Discussion}

The findings of this study revealed that about $20.7 \%$ of the respondents every utilized youth friendly Reproductive health service in the last 12 months in the study area. This was almost similar with the result of study done in East Gojjam, Machakel district which was 21.5\% [21].

But the result from the current study was lower when compared to the other studies conducted in different part of Ethiopia which was $69.1 \%$ in Mekelle town, $63.8 \%$ in Harar $38.5 \%$ in Hadiya $32.2 \%$ in Bahir dar, $34.3 \%$ in Albukoworeda and $37.2 \%$ in Goba town [22-28] respectively. The difference might be due to the difference in socio-cultural and openness of the study participants in Harar and Mekellein comparison with this study area [22, 23].

The prevalence of youth friendly reproductive health service utilization in this finding is also lower than the institutional based study conducted in Malawi (62\%), in Nigeria (51\%) and Bureti city, Kenya (38.5\%) [29, 30]. This higher in utilization of YFRHS in those areas than the result of this study was probably the foreign countries might have more advanced in health care delivery than that of Ethiopia in having availability and accessibility of health facility, urbanrural residence and transportation difference between the countries and with better infrastructures.

Among those youths ever utilized youth friendly reproductive health services, the study showed the main services utilized $13.8 \%$ used VCT service making it the most utilized followed by IEC $10.9 \%$. It is consistence with many studies in Harar, Metekel and Albukoworeda. In this study the most frequently visited health facilities by the respondents were government health centers $(14 \%)$. This is less when compared with findings from studies conducted in Awabel district, Goba and sodo town [31, 28, 32]. Contrarily to these findings, respondent at Jimma (26.7\%) and Harar $(64.5 \%)$ reported that family guidance association of Ethiopia was frequently visited health institution [10, 23]. This is, may be, due to poor collaboration with stakeholders, even though government health center had privacy and confidentiality, accessibility to trained health provider and affordability of cost in the study area.

In this study youths in the age groups of 15 - 19 years were 0.38 times less likely to use youth friendly reproductive health services than youth of age 20-24 years $[\mathrm{AOR}=.380$, $95 \% \mathrm{CI}=(0.176-0.819)]$. This finding is consistent with the study conducted in Bahirdar, Jimma and Metekelin which youths within age groups of $20-24$ years were 2.31 times more likely to use services than youth of age 15 - 19 years $[11,30,31]$. This is probably due to the fact that the older youths apply what they heard about youth reproductive health services and more likely to utilize the service when compared to youths of age 15 - 19 years old..

The finding of this study also showed that grade nine students were 3 time more likely utilized youth friendly reproductive health services as compared to the other group. Butthis finding is inconsistent with the study conducted in Bale zone, Goba town in which Grade nine students were 91\% less likely to use YFSRHS compared to grade eleven and twelve students [27]. This difference is probably due to the time to start for reproductive health information and secondary behavioral change and when they come to high school to the new environment, youths vulnerable to reproductive health problems that enforces the utilization.

Another predictor variable that shown significant association in this study was student's previous residence status. Accordingly, students who were living in urban were 0.53 times less likely to utilize YFRHS as compared to students when previously living from rural $[\mathrm{AOR}=.527,95 \%$ $\mathrm{CI}=(0.3-0.926)]$. This finding is not line with a survey report of EDHS in which Urban youths were more likely to utilizes YFRHS than rural youths [25]. This is most probably due to the fact that student who had used youth friendly reproductive health services have got new knowledge, adequate information, and more access to proper counseling offered from health professionals while they came to urban area.

This study also indicated that utilization of the youth friendly reproductive health services was high in respondents who had youth friendly reproductive health service facility around their living area were as those who had the services in their living area were 7 times more likely utilized youth friendly reproductive health service as compared to those who had no youth friendly service facility in their living area $[\mathrm{AOR}=7.1,95 \% \mathrm{CI}=(2.676$ 19.015)]. This is probable due to the reason that those respondent who have the opportunity to access health facility around their living can get exposure to health education related to youth friendly reproductive health services at the time of visit and thus get access to learn about the types, benefits and availabilities of youth friendly reproductive health service facility around their living.

In this study more than half $54.5 \%$ of the respondents heard about YFRHS from school followed by health care provider $48.9 \%$. The finding was similar with study finding conducted in Harar which shows majority of respondents $72.4 \%$ heard information about YFRHS from school 31.5\% followed by $22.8 \%$ from radio broadcasts [23]. The probability may be due to school teachers had better knowledge about youth friendly reproductive health services to provide the information in the study area.

Among those who did not use the service about 107 $(35.9 \%)$ of the respondents reported that the reason not to use YFRHS was because they do not want the services or they 
were followed by do not know where to get the services 77 $(25.8 \%)$ and distance of the health services 35 (11.8\%). This result is almost similar with the result of study done in Harar were the reasons mentioned for non-use were the youths did not know where to go for the services $(43 \%)$ followed by distance (18.7\%) [23]. Another reason mentioned by the study participants for not to utilize the services in this study were, inconvenient working hours $24(8 \%)$, fear of being seen by families or peoples whom they know 20 (6.7\%). This is consistent with the studies in Harar, Bahir dar and Albuko Woreda that the Study participants claimed that: youth friendly reproductive health service working hours were inconvenient $(31.8 \%)$; there is payment for the services $(28.4 \%)$ and fear of being seen by parents or people [23, 25, 26]. This is also consistent with the study done in Kenya on the barriers of utilization of reproductive health services which indicated that $31 \%$ of the students mentioned inconvenience hours as one of the reasons as barriers to utilizes the reproductive health services [30].

\section{Limitation of the Study}

Since study was conducted on school youths the generalization of the result for out of school youths may not possible. In addition collecting data through selfadministered questionnaire by itself has subjectivity and not involving quantitative methods also its own limitation to the data.

\section{Conclusions}

Generally the utilization of youth friendly reproductive health services among secondary and preparatory school students in Ambo town was low. Lack of information where to get the service, distant to youth friendly service delivery institution, and fear of parents are barriers of utilization of youth friendly reproductive health services. Age, grade of the students, previous residence status and existence of youth friendly reproductive health services were factors found to be associated with youth friendly reproductive health services.

\section{Abbreviations}

$\begin{array}{ll}\text { GBV } & \text { Gender Based Violence } \\ \text { IEC } & \text { Information, Education and Communication } \\ \text { RH } & \text { Reproductive health } \\ \text { RHS } & \text { Reproductive health service } \\ \text { SRH } & \text { Sexual and reproductive health } \\ \text { SPSS } & \text { Statistical Package for Social Science } \\ \text { STI } & \text { Sexually transmitted infection } \\ \text { VCT } & \text { Voluntary counseling and testing } \\ \text { YFRHS } & \text { Youth friendly reproductive health }\end{array}$

\section{Authors' Contributions}

All authors contributed a great role with regard to the conception, design, data collection, analysis, interpretation and wrote the draft manuscript.

All authors read and approved the final manuscript.

\section{Competing Interests}

The authors declare that they have no competing interests.

\section{Funding}

Funding for the research was provided by Ambo university research consultancy and community service director office. Besides financial support, the funding body had no role in the design of the study and collection, analysis, and interpretation of data and in writing the manuscript.

\section{Acknowledgements}

The Authors would like to thank AU for allocating fund to conduct the study. We would also like to express our deepest appreciation to all individuals who supported us during this research work for their indispensable contributions. Last but absolutely not the least, the contribution of the study participants is greatly appreciated.

\section{References}

[1] UNFPA., Improving reproductive health service, 2010.

[2] Ethiopia, M. o. H., National adolescent and youth reproductive health strategy, Addis Ababa, 2007 -2015./ file manager/files/Ethiopia/ayrh_strategy.pdf, July 2016.

[3] Commission, F. D. R. o. E. P. C., Summary and Statistical Report of the 2007 Population and Housing Census: Population size by age and sex, 2008.

[4] USAID and IFHP, Reproductive health integrated program, December 2016.

[5] Health, E. F. M. o., National Adolescent and Youth Reproductive Health Strategy, 2006.

[6] UNFPA, Adolescent sexual and reproductive health, November 2014.

[7] Cortez R, Quinlan-Davidson M, and Saadaat., Challenges for adolescent's sexual andreproductive health within the contex of universal health coverage, September 2014.

[8] Bukenya N. Justine, et al., Health facilities' readiness to provide friendly reproductive health services to young people aged 10-24 years in Wakiso district, Uganda 2017.

[9] A, A., Youth reproductive health problems and service preferences, Assebe Teferi, west hararghe. April, 2004.

[10] WHO, Report of programming for adolescent health and development study group, Geneva, 1999.

[11] Aboma Motuma, Youth-friendly health services utilization and factors in Harar, Ethiopia. Harar Bulletin of Health Sciences Extracts Number 4, 2012. 
[12] Tegegn A, Yazachew M, and G. Y., Reproductive health knowledge and attitude among adolescents: a community based study in Jimma Town, Southwest Ethiopia. EJHD, 2008.

[13] Kennedy EC, et al., "Be kind to young people so they feel at home": a qualitative study of adolescents' and service providers' perceptions of youth-friendly sexual and reproductive health services in Vanuatu. BMC health services research, 2013.

[14] C., H., et al., Adolescent Reproductive Health in Ethiopia, Adolescent Women's Need for and Use of Sexual and Reproductive Health Services in Developing Countries, August 2011.

[15] Ed School, et al., Assessment of Youth Reproductive Health Programs in Ethiopia. July, 2011.

[16] Central Statistical Agency, E., Ethiopia Demographic and Health Survey, 2016.

[17] Health., T. f. d. r. o. E. m. o., Health sector transformation plan (2015) 2015/16 - 2019/20 (2008-2012 EFY), 2015.

[18] Office, Ambo Education office, Students statistics, 2017.

[19] Atitegeb Ayehu, T. K., and G. Hailu, Level of Young People Sexual and Reproductive Health Service Utilization and Its Associated Factors among Young People in Awabel District, Northwest Ethiopia. PLOS ONE | DOI: 10.1371/journal.pone.0151613, 2016.

[20] Jarssa, A. g., T. m. lodebo, and J. a. suloro, Youth friendly sexual and reproductive health services utilization and associated factors among school youths in goba town, bale zone, southeast ethiopia 2017. 4 (3).

[21] Amanuel Alemu Abajobir and A. S. Abajobir, Reproductive health knowledge and services utilization among rural adolescents in east Gojjam zone, Ethiopia: a communitybasedcross-sectional study BMC Health Services Research 2014.

[22] Kalayu kahsay, Semarya berhe, and M. Alemayehu, Utilization of youth friendly services and associated factors in Mekelle town, Tigray, northern Ethiopia International Journal of Therapeutic Applications, 2016, v. 33.
[23] Aboma Motuma TS, Gudina Egata and Abera Kenay. Utilization of youth friendly services and associated factors among youth in Harar town, east Ethiopia: a mixed method study. BMC health services research. 2016; 16 (1): 272.

[24] Akililu jaleta, Alemayehu assefa, and M. amentie, Youth friendly reproductive health service utilization and associated factors among youths in metekel zone, north west Ethiopia 2017. v 2 .

[25] Meskerem Abebe WA. Utilization of Youth Reproductive Health Services and Associated Factors among High School Students in Bahir Dar, Amhara Regional State, Ethiopia. Open Journal of Epidemiology. 2014; 4, (69-75): http://dx.doi.org/10.4236/ojepi.2014.42012.

[26] Wubetu G/Hiwot, Prof (Dr) P. Sureder Reddy, and T. Awoke, Assessment of Youth Friendly Services Utilization And Associated Factors Among Young People in Albuko Woreda, South Wollo Zone, Amhara Region, Ethiopia, 2014, 6 (4).

[27] Degefa Helamo Samuel Kusheta, et al., Utilization and Factors Affecting Adolescents and Youth Friendly Reproductive Health Services among Secondary School Students in Hadiya Zone, Southern Nations, Nationalities and Peoples Region, Ethiopia Int J Pub Health Safe 2017.

[28] Alemayehu Gurure jarssa tmlajas. Youth friendly sexual and reproductive health services utilization and associated factors among school youths in goba town, bale zone, southeast ethiopia, European journal of biomedical and pharmaceutical sciences. 2017; 4 (3): 335-48.

[29] Youth Friendly Services in Malawi: Do youth know of and use these services?(brief health policy project). 2015: http://www.e2aproject.org/publications-tools/pdfs/evaluationyfhs-malawi.pdf.

[30] Nancy. u. luvai, M. kipmerewo, and K. o. onyango, Utilization of youth friendly reproductive health services among the youth bureti sub county in kenya, 2017.

[31] Atnafu Natnael, Youth friendly service utilization and associated factors among preparatory school students in sodo town, southern nations, nationalities and peoples region, Ethiopia, 2017. 